of anesthesia in hypertensive patients when considering the poor value of the bispectral index, of end-tidal concentration of sevoflurane or its duration of administration in predicting the depth of anesthesia and the hemodynamic reaction to nociceptive stimuli.

G. Vial

N. Nathan

M. Benrhaiem

A. Peyclit

P. Feiss

Limoges, France

References

1 Low JM, Harvey JT, Prys-Roberts C, Dagnino J. Studies of anaesthesia in relation to hypertension VII: Adrenergic responses to laryngoscopy. Br J Anaesth 1986; 58: 471-7.

2 Hickey S, Cameron E, Asbury AJ. Cardiovascular response to insertion of Brain's laryngeal mask. Anaesthesia 1990; 45: 629-33.

3 Iwasaki H, Omote T, Hamada I, Nakamura I, Namiki $A$. Acute pulmonary edema in five patients undergoing sevoflurane anesthesia. (Japanese) Masui 1992; 41: 1183-7.

4 Ebert TJ, Muzi M, Lopatka CW. Neurocirculatory responses to sevoflurane in humans. A comparison to desflurane. Anesthesiology 1995; 83: 88-95.

5 Yli-Hankala A, Randell T, Seppälä T, Lindgren L. Increases in hemodynamic variables and catecholamine levels after rapid increase in sevoflurane concentration. Anesthesiology 1993; 78: 266-71.

6 Hall JE, Ebert TJ, Harmer M. Sevoflurane adult gaseous induction: an evaluation of stage II and its haemodynamic consequences. Br J Anaesth 1999; 82: A452.

7 Constant I, Dubois MC, Piat V, Murat I. Heart rate and blood pressure variability during halothane or sevoflurane anesthesia in children. Anesthesiology 1998; 89: A1253.

\section{Transthoracic echocardiography pre-, intra-, and postoperatively}

To the Editor:

We fully agree with Hadiç and co-authors concerning the use of transthoracic echocardiography (TTE) in the perioperative period. ${ }^{1}$ In addition to its use pre- and postoperatively, we use TTE as an intraoperative noninvasive hemodynamic monitor in patients with severe cardiac disease undergoing surgical procedures in regional anesthesia. Thus, our indications for perioperative use of TTE include: 1) preoperative TTE to evaluate unclear cardiac status, e.g. clinical suspicions of aortic stenosis, in patients needing urgent surgery but no immediately available cardiologist-echocardiographer, 2) intraoperative TTE to monitor patients with severe cardiac disease undergoing surgery in regional anesthesia, and 3) postoperative TTE in patients with severe hemodynamic instability occurring after extubation. The use of TTE by anesthesiologists prevents unnecessary delays of surgery, allows extended noninvasive hemodynamic monitoring during regional anesthesia, and facilitates postoperative patient care. To obtain appropriate information from TTE, anesthesiologistsechocardiographers performing TTE need formal training in the transthoracic echocardiographic approach.

Miodrag Filipovic MD

Manfred D. Seeberger MD

Luzius Steiner

Karl Skarvan MD

Basel, Switzerland

Reference

1 Hadiç A, Vloka JD, Koorn R, Thys DM Transthoracic echocardiography in perioperative medicine (Letter). Can J Anesth 1999; 46: 616.

\section{Axillary blockade by the targeted method. Added benefit?}

To the Editor:

We wish to comment on the article by KorscielniakNielsen et al. ${ }^{1}$ regarding upper limb brachial plexus blockade by the targeted approach. First, the authors claim that this approach reduces total anesthetic time compared with the single injection approach because block supplementation for the single-injection recipients was time-consuming. However, the success rates for complete blockade in the single-injection group was only $54 \%$. Even when the author excludes those supplementary blocks unnecessary for surgery, success increased to only $65 \%$. This is a high failure rate. Most studies produce successful blockade in $85-100 \%$ of subjects $^{2-6}$ and the single-injection technique is faster. Second, $22 \%$ of the targeted group experienced tourniquet pain, compared with $4 \%$ in the single-injection group. As brachial plexus blockade is the regional technique of choice for prolonged surgery, tourniquet pain to this degree may become a limiting factor when using the targeted approach. Third, the author states that the 
targeted method may be safer, as $17 \%$ of single injection recipients developed signs of intravascular injection and local anesthetic toxicity. This incidence is high, 5,6 perhaps due to the large volumes of mepivacaine $(80 \mathrm{~mL})$. Would smaller volumes $(40-60 \mathrm{~mL})$, result in a lower incidence of complications?

Finally, is it logical to assume that injection of four individual nerves may increase the incidence of complications four fold, for a technique that is generally very well served by a single-injection approach. We feel that the targeted method does not have as many benefits as the author claims, when compared with the classic single-shot approach.

Margaret M. Coleman FFARCSI

Fergal Day FFARCSI

Toronto, Ontario

References

1 Koscielniak-Nielsen ZJ, Nielsen PR, Sørensen T, Stenør $M$. Low dose axillary block by targeted injections of the terminal nerves. Can J Anesth 1999; 46: 658-64.

2 Selander D. Axillary plexus block: paresthetic or perivascular (Editorial). Anesthesiology 1987; 66: 726-8.

3 Horlocker TT, Kufner RP, Bishop AT, Maxson PM, Schroeder DR. The risk of persistent paresthesia is not increased with repeated axillary block. Anesth Analg 1999; 88: 382-7.

4 Schroeder LE, Horlocker TT, Schroeder DR. The efficacy of axillary block for surgical procedures about the elbow. Anesth Analg 1996; 83: 747-51.

5 Palve H, Kirvela O, Olin H, Syvalabti E, Kanto J. Maximum recommended doses of lignocaine are not toxic. Br J Anaesth 1995; 74: 704-5.

6 Pearce $H$, Lindsay D, Leslie $K$ Axillary brachial plexus block in two hundred consecutive patients. Anaesth Intensive Care 1996; 24: 453-8.

\section{REPLY:}

The main object of Drs. Coleman and Day' letter is the low success rate of axillary block by single injection in our study. They refer to one editorial view, ${ }^{2}$ and four studies, ${ }^{3-6}$ neither randomized nor controlled. In a review of RCTs of axillary block in the Cochrane Controlled Trial Register, Medline and Embase between 1966 and 1998, the average success rates were: single injection ( 13 RCTs - 67\%), catheter injection (9 RCTs - 61\%), double injections (9 RCTs - 73\%, multiple injections (5 RCT's 84\%) whereas almost all retrospective studies of axillary block in the same period reported higher success rates.
Tourniquet pain was a disturbing factor and we did not recommend low doses for a standard axillary block: surgical analgesia is better after four targeted, than after one large injection. Drs. Coleman and Day postulate that smaller volumes $(40-60 \mathrm{ml}$ ) by single injection are as effective as a large volume $(80 \mathrm{ml})$. The only $R C T$ addressing this question shows that they are equally ineffective. ${ }^{2}$

Theoretically, four injections are more dangerous than a single injection. However, assessment of the needle-nerve distance, which is possible with a nerve stimulator, use of atraumatic needles (pencil-point) and injections above and below the axillary artery reduce the risks of nerve damage and of accidental arterial puncture. The risk of accidental intravenous injection may be increased, but is compensated for by a smaller dose of a local anesthetic per injection. Therefore, while a single large dose intravascular injection results in loss of consciousness, grand-mal seizures and/or cardiac arrest, the small dose produces tachy- or bradycardia, circumoral numbness, beadache and muscle twitches.

Zbigniew Koscielniak-Nielsen MD FRCA

Copenhagen, Denmark

References

1 Koscielniak-Nielsen ZJ, Stens-Pedersen HL, Lippert FK Readiness for surgery after axillary block: single or multiple injection techniques. Eur J Anaesthesiol 1997; 14: 164-71.

2 Vester-Andersen T, Christiansen C, Sørensen M, Kaalund-Jørgensen HO, Saugbjerg P, Schultz-Møller K Perivascular axillary block II: influence of injected volume of local anaesthetic on neural blockade. Acta Anaesthesiol Scand 1983; 27: 95-8.

\section{Sevoflurane sedation}

To the Editor:

I would like to detail a method of sedation for reader comment and feedback. Volatile agents are not commonly used for sedation for a number of reasons which include difficulty of administration and patient intolerance. Some recent publications, however, have suggested that Sevoflurane might be used in this capacity. ${ }^{1,2}$

Nasal prongs with an entidal sampling tube (Salter Labs - REF 4707F) are attached to the common gas outlet of an anesthesia machine. The nasal prongs are placed on the patient in the usual manner, and then a standard oxygen mask (Airlife \#00121) is also fitted 